\section{ENVIRONMENTAL ANALYSES}

\subsection{Palynology}

Catherine Flitcroft and Lucy Verrill

Two peat monoliths were removed, from Trench 14 (Illus 34, Illus 35) and Trench 5 (which later became incorporated within Trench 15; position indicated on Illus 3, Illus 36), and a sequence of Kubiena tins were used to sample the relict soil profile in Trench 15 (Illus 8 - samples C1-4).

\subsubsection{Methodology}

Sub-samples of one cubic centimetre from the Trench 15 (CLF-15) and Trench 14 (CLF-14) peat column monoliths, and from the soil profile in Trench 15 (CLF-SP), were processed for pollen analysis using standard techniques (Moore et al 1991). Identification used the pollen key in Moore et al (1991) and reference material. For CLF-14 and CLF-15 counts, a total land pollen count (TLP: total identified pollen excluding spores and aquatics) of 500 was aimed for; where this was not possible a minimum count of 300 was obtained. For CLF-SP counts, preservation was generally poorer and a minimum TLP count of 300 per level was obtained. Pollen diagrams were constructed using Tilia and TGView.

\subsubsection{Radiocarbon dates}

AMS radiocarbon dates of six bulk peat samples were taken from the peat monoliths in Trenches 14 and 15 in order to provide dates for the pollen

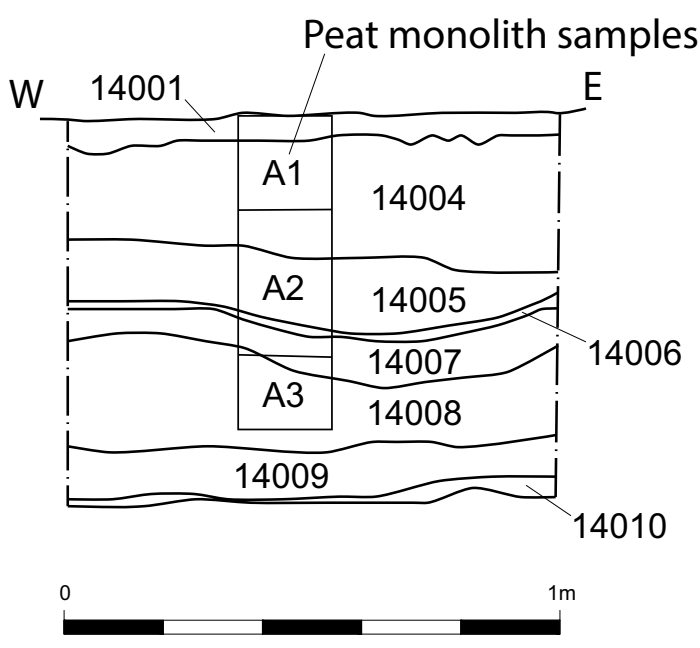

Illus 34 Trench 14 south-facing section

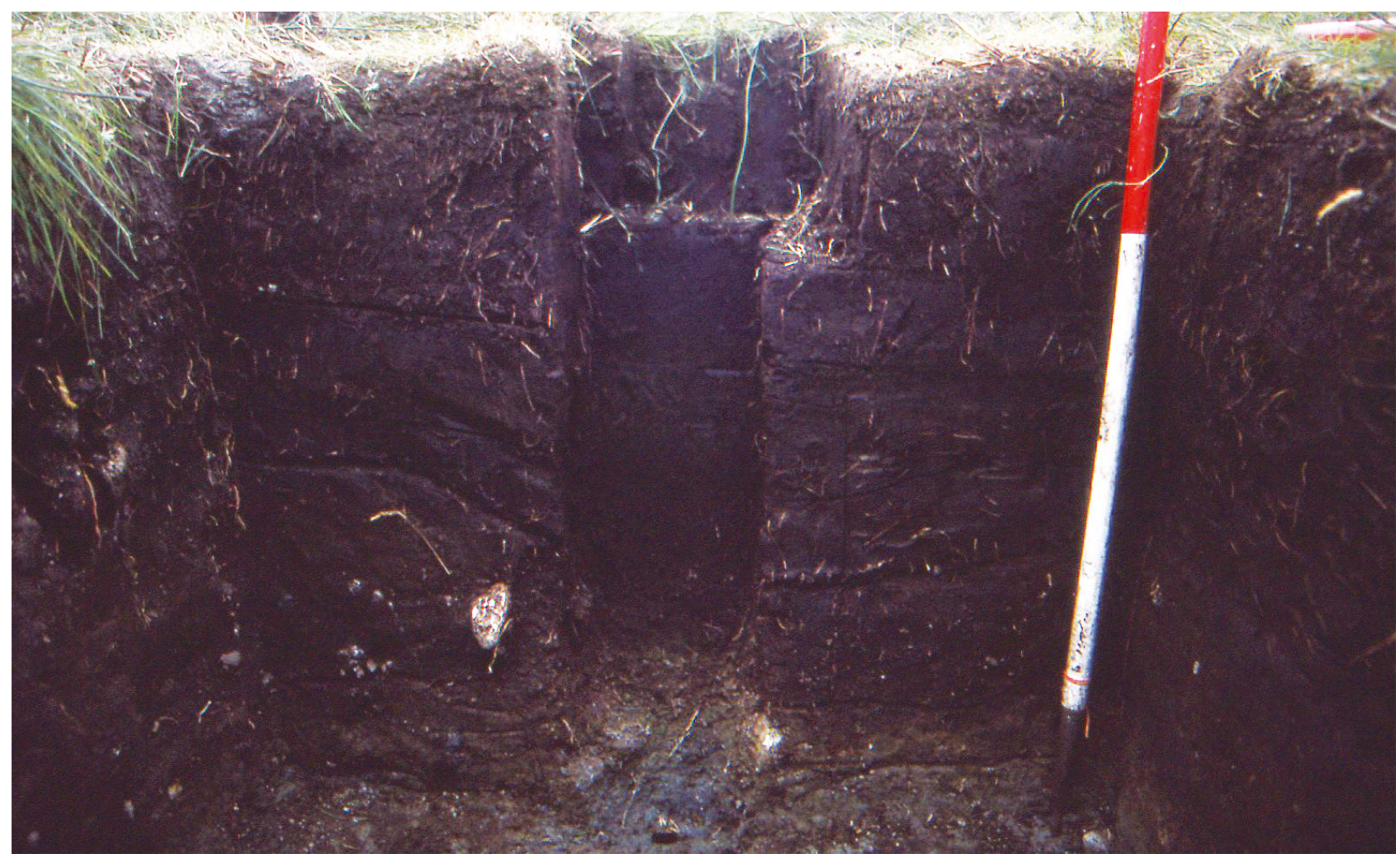

Illus 35 Trench 14 peat monolith position 


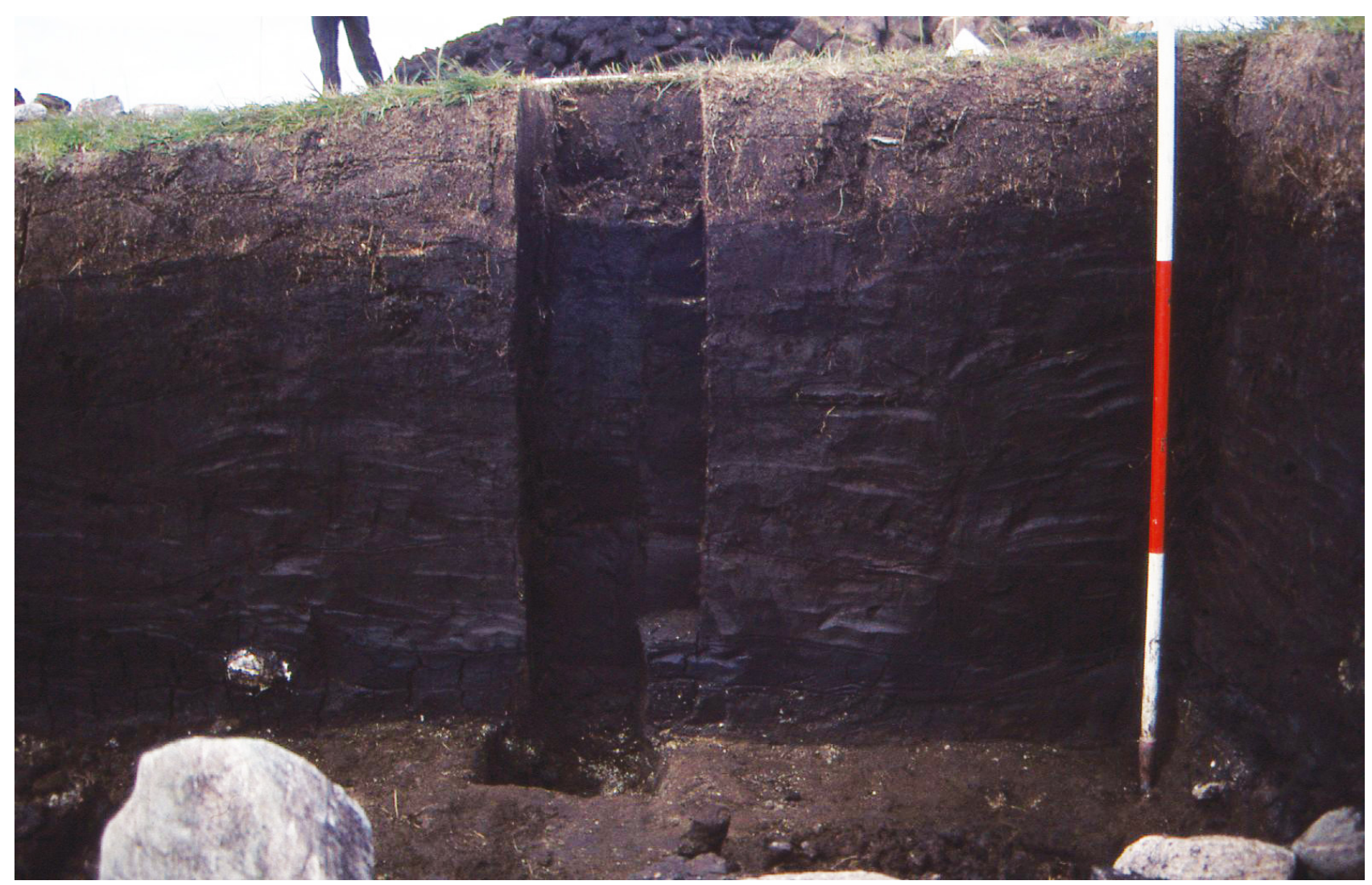

Illus 36 Trench 15 peat monolith position

sequences. The humin fraction only was dated. These were assayed at the Oxford Radiocarbon Accelerator Unit in 2001 and the dates have been recently recalibrated using $\mathrm{OxCal}$ 4.4.2. Results are shown in Table 1 and Illus 37.

Samples OxA-10091 and OxA-10120 were taken from the lowest level of peat growth in each monolith, at the interface between the palaeosol and the first identified natural peat growth. The dates indicate that peat growth in this area began in the first millennium BC and was not simultaneous across the area, since peat inception began earlier at the base of the slope in Trench 14 (Oxa-10120, 750-380 cal BC) than further upslope in Trench

Table 1 Radiocarbon dates. Calibrated using OxCal v.4.4.2. IntCal13 atmospheric curve (Reimer et al 2020)

\begin{tabular}{lccccc} 
Lab code & Trench & $\begin{array}{c}\text { Depth within } \\
\text { peat column }\end{array}$ & $\begin{array}{c}{ }^{14} \mathrm{C} \text { age } \\
\text { (years BP) }\end{array}$ & $\begin{array}{c}\text { Calibrated date range at } \\
95 \% \text { probability }\end{array}$ & $\delta^{13} \mathrm{C}(\%$ ) \\
OxA-10089 & 15 & $200-210 \mathrm{~mm}$ & $234 \pm 34$ & $\begin{array}{c}1520-1560 \mathrm{cal} \mathrm{AD} \\
1630-1690 \mathrm{cal} \mathrm{AD}\end{array}$ & -27.9 \\
& & & & $\begin{array}{c}1730-1810 \mathrm{cal} \mathrm{AD} \\
1930-1950 \mathrm{cal} \mathrm{AD}\end{array}$ & \\
\hline OxA-10090 & 15 & $590-600 \mathrm{~mm}$ & $1628 \pm 37$ & $360-550 \mathrm{cal} \mathrm{AD}$ & -27.2 \\
\hline OxA-10091 & 15 & $1040-1050 \mathrm{~mm}$ & $2222 \pm 37$ & $390-170 \mathrm{cal} \mathrm{BC}$ & -28.7 \\
\hline OxA-10118 & 14 & $200-210 \mathrm{~mm}$ & $1370 \pm 40$ & $600-780 \mathrm{cal} \mathrm{AD}$ & -26.4 \\
\hline OxA-10119 & 14 & $340-350 \mathrm{~mm}$ & $1805 \pm 45$ & $120-370 \mathrm{cal} \mathrm{AD}$ & -28.2 \\
\hline OxA-10120 & 14 & $520-530 \mathrm{~mm}$ & $2380 \pm 40$ & $750-380 \mathrm{cal} \mathrm{BC}$ & -29.9
\end{tabular}


15 (OxA-10091, 390-170 cal вс). The uppermost dates (OxA-10089, OxA-10118) were taken from immediately beneath the modern turf and roots, while the centre dates (OxA-10090, OxA-10119) provided additional control for the pollen sequence. These dates provide a terminus ante quem for the activity at Calanais Fields and suggest that the structures excavated and described above may be Late Bronze Age/Early Iron Age or earlier in date.

\subsubsection{Results}

Percentage pollen diagrams showing selected taxa are presented in Illus $38-40$. Shaded curves show $\times 10$ exaggeration and a dot denotes presence. Five pollen assemblage zones (prefixed 'PAZ') were identified.

\section{Pollen stratigraphy interpretation}

The sequence is interpreted as opening in the Late Bronze Age, pre-600 BC, based on extrapolation from

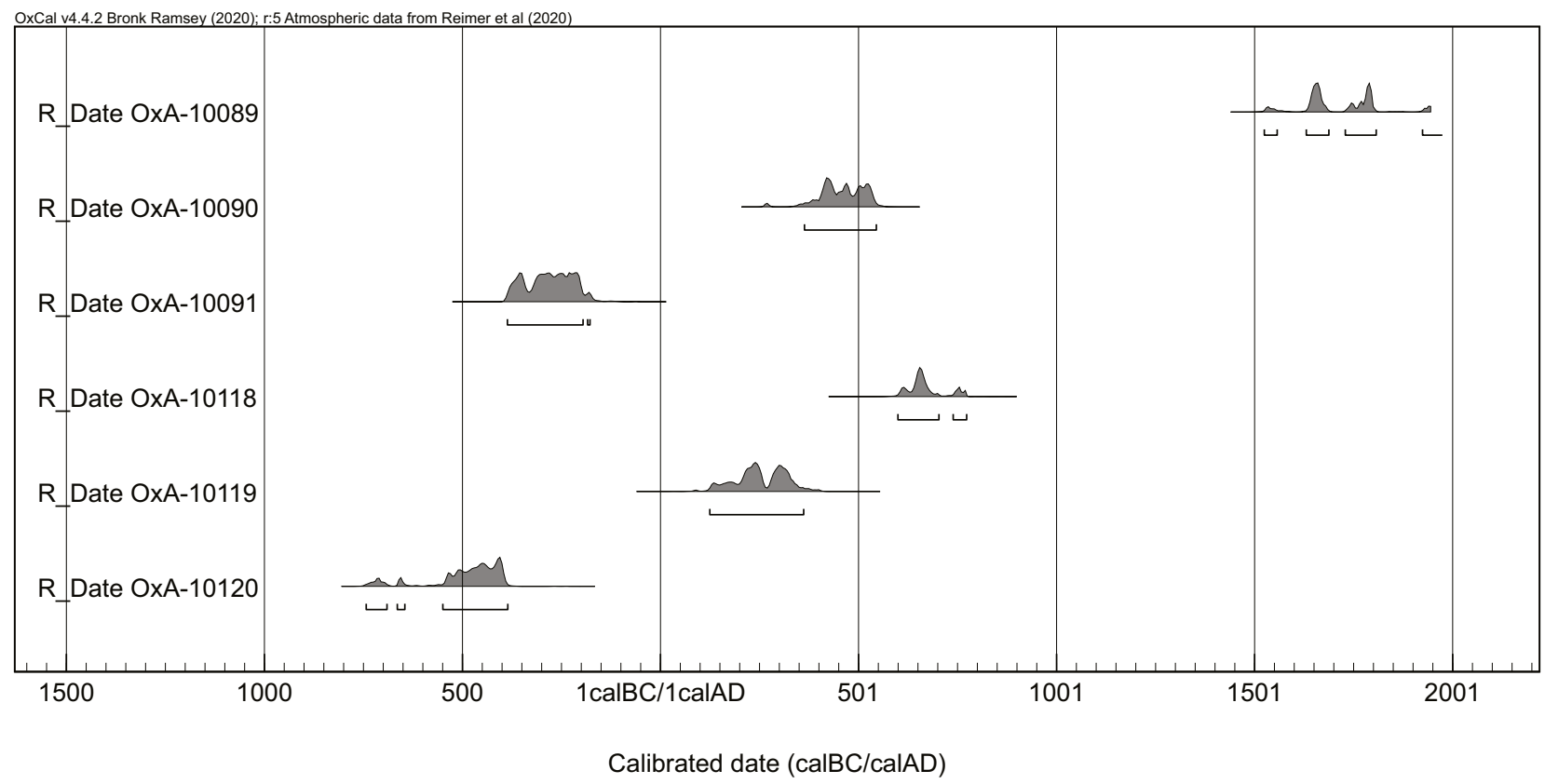

Illus 37 Radiocarbon dates

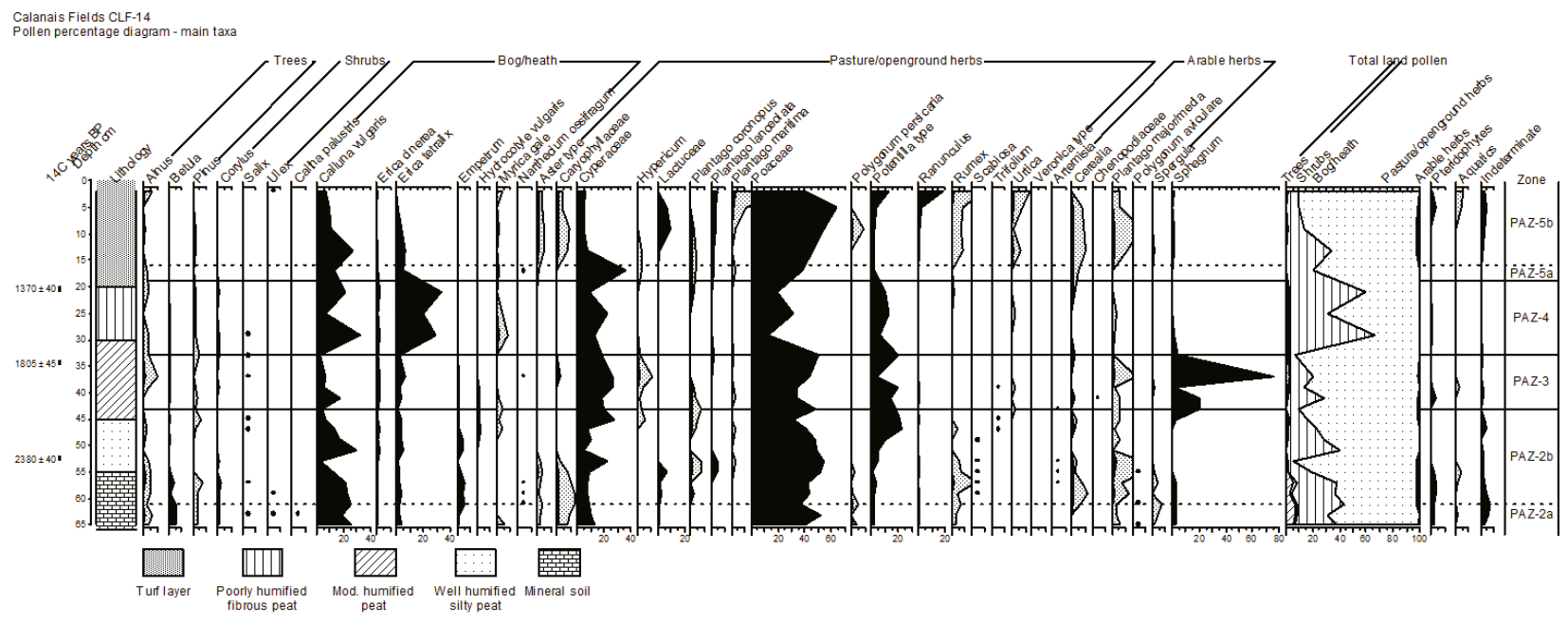

Illus 38 Pollen percentage diagram CLF-14 


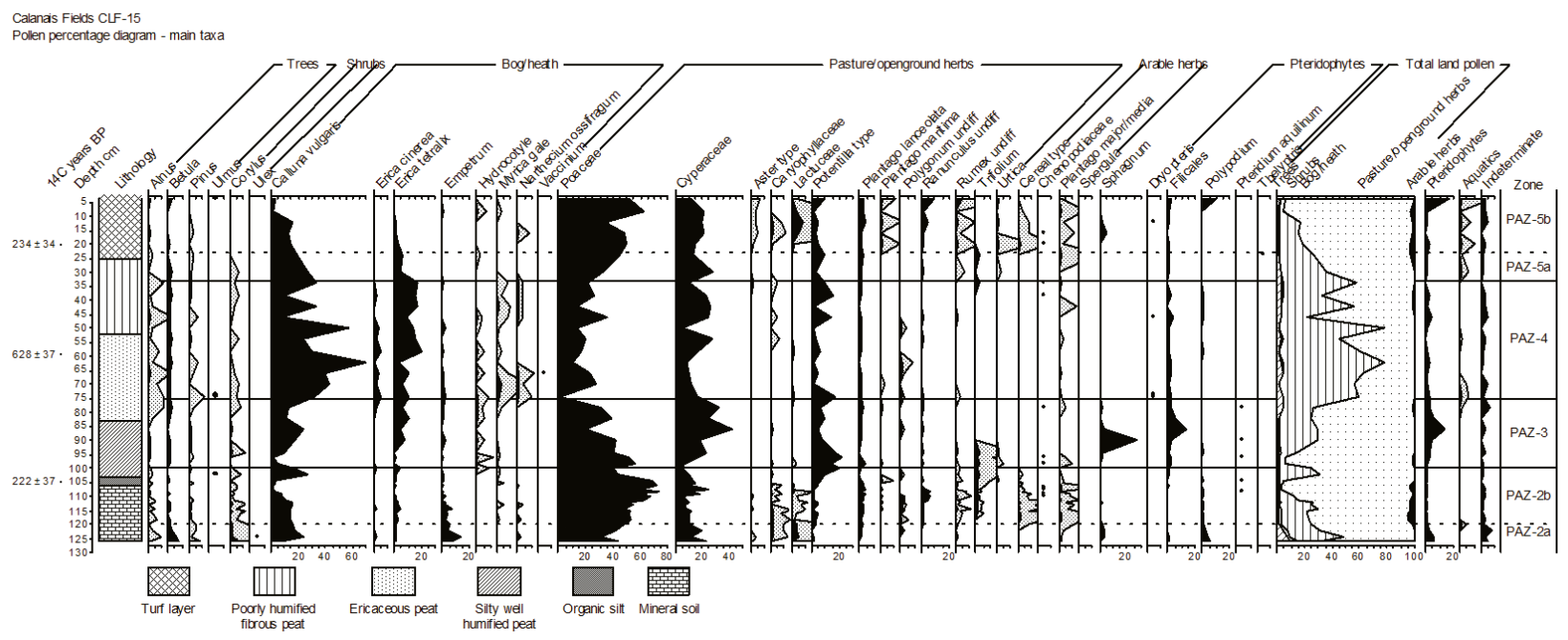

Illus 39 Pollen percentage diagram CLF-15

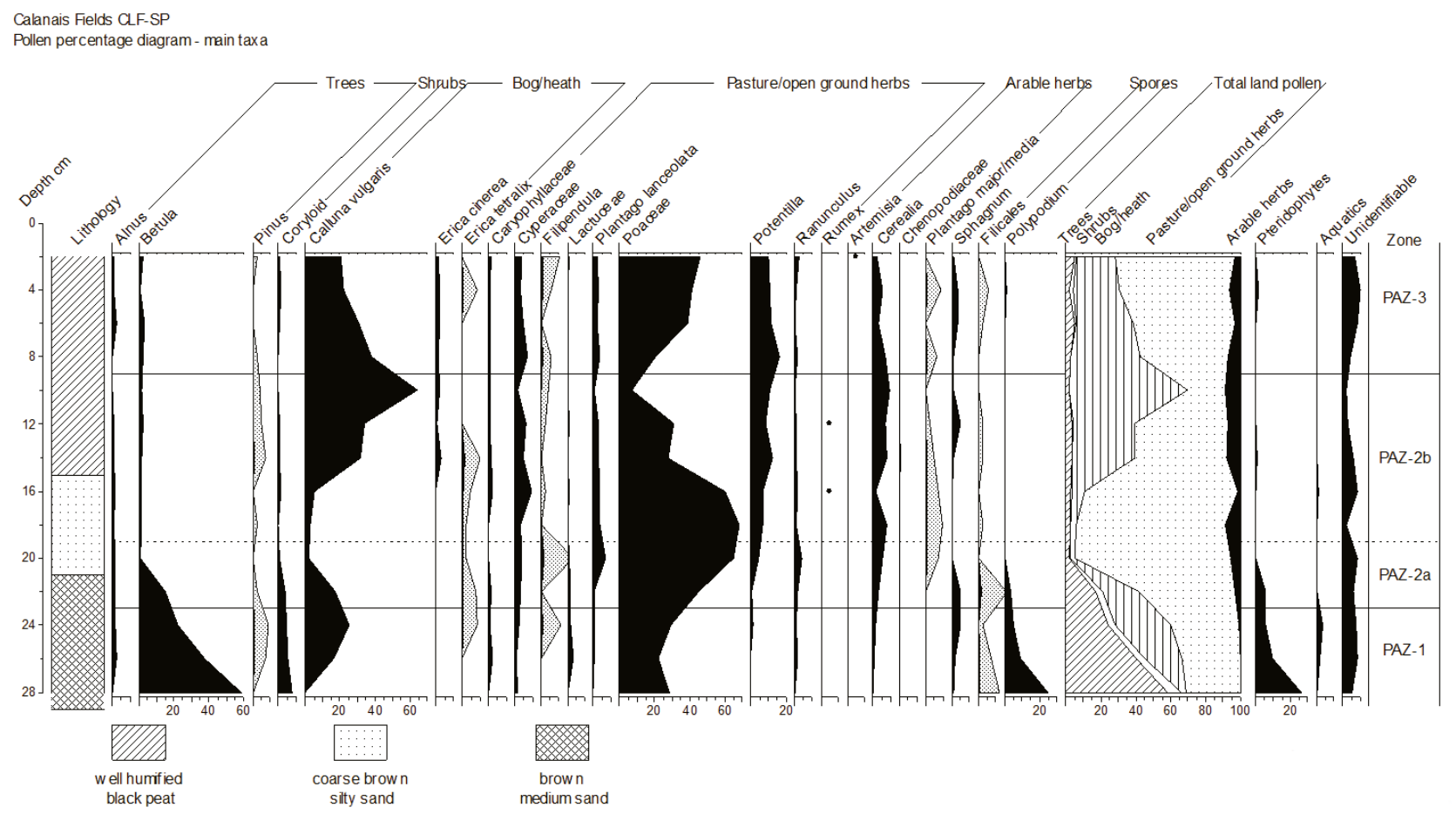

Illus 40 Pollen percentage diagram CLF-SP

radiocarbon-dated basal peat. The fall in tree pollen corresponds well to the early part of subzone $\mathrm{CaN}-3 \mathrm{c}$ at Tob nan Leobag where a phase of agricultural activity was recorded (Bohncke 1988: 456).

A mixed arable and pastoral agricultural regime is evident. Cereal-type pollen grains were identified in the PAZ-2 assemblages. Both Hordeum-type and Avena-Triticum-type sensu Andersen (1979) were identified but are not distinguished in the diagrams.
While pollen from some wild grasses is included in the Hordeum-type group (Andersen 1979), the frequency of cereal-type pollen grains in the profiles and the presence of Avena-Triticum-type grains support an interpretation of cereal cultivation. The particular cultivars cannot be confidently inferred from pollen data.

Peat initiation commenced earlier in Trench 14 (downslope) than in Trench 15, which accounts for 
the earlier decline in cereal-type pollen in CLF-14 than in CLF-15. Cereal-type pollen and associated weeds decline in CLF-15 at the soil-peat interface $(106 \mathrm{~cm})$, and cereals disappear entirely at $101 \mathrm{~cm}$, just before the PAZ2b/3 boundary. Cereal-type pollen continues to be recorded in PAZ-3 in the CLF-SP profile. This is probably due to the disturbed nature of the context. Infilling of the ditch feature (C15036) by peaty material (C15002) may have redistributed sediment from elsewhere within the site.

By $c 200$ вС agricultural activity in the locality had ceased. This coincided with a marked peak in Sphagnum (bog moss) representation and the appearance of Hydrocotyle vulgaris (marsh pennywort), both of which are typical of the wetter areas within blanket bog. This apparent phase of increased bog growth is seen in both CLF-14 and CLF-15. There is a Sphagnum peak at $c 2000$ в in the Tob nan Leobag profile and increases in wet-loving species in all profiles (Bohncke 1988: 457-8). Together with the evidence from Calanais Fields, a picture develops of increased wetness leading to the acceleration of local blanket bog growth and the expansion of wet moorland. Arable indicators and occasional cereal pollen grains continue to be recorded in PAZ-3 at CLF-14. It is possible that agriculture continued in the locality, but not in the immediate vicinity of the field system; perhaps in areas remaining free of blanket peat. Asynchronous growth of blanket peat across the field system and indeed elsewhere in the Calanais area (see eg Bohncke 1988) may have necessitated phases of moving or expanding of the field systems into previously uncultivated areas.

By $c$ AD 200 the period of increased local wetness ceased, and major expansions in pollen taxa such as Calluna vulgaris (ling), Erica tetralix (cross-leaved heather) and Myrica gale (bog myrtle) indicate the replacement of grassland by heath. This situation is reversed by the PAZ 4/5 boundary at around AD 900, at which a renewal of agricultural activity is apparent. Poaceae (grasses) increase and pastoral weeds such as Rumex spp. (docks), Plantago spp. (plantains) and Urtica (nettles) reappear. This resumption of agriculture can be correlated with the early Norse occupation of the islands. By around AD 1000 cereal cultivation resumed, with cereal-type pollen including both Hordeum-type and AvenaTriticum-type recorded.

Continued mixed agriculture is evident in the upper subzone. Medieval and later occupation of the Calanais township is documented and the pottery and archaeobotanical assemblages from Trench 3 show that this part of the site was utilised in late medieval/post-medieval times (see Sections 4.4 and 5.1 below). There are remains of undated blackhouse-type structures visible within the area under consideration; subsistence arable agriculture associated with the habitation of these domiciles is evident in PAZ-5b. By the top of both profiles, grassland and pastoral taxa are the dominant vegetation types, with reduced bog and heath vegetation.

\subsection{Soil tests}

\section{Catherine Flitcroft}

Samples for phosphate and loss on ignition (LOI) tests were taken across the palaeosol in a grid system in Trenches 4, 6, 7, 8, 9, 11 and 15; and through selected sections in Trenches 14 and 15. The intention was to analyse the lateral variation of the palaeosol across the site, and in Trench 15 assess spatial variation across the trench's various structures and either side of the field boundary wall. Samples were also taken from within structure C15008 and from around a series of furrows cut into the palaeosol (C15013, C15012, C15011). The samples were collected following removal of the overlying peat.

\subsubsection{Methodology}

\section{Phosphate analysis}

Air-dried samples were analysed for total phosphate concentration using ignition-hydrochloric phosphate digestion followed by the one-step vanadomolybdate extraction method (Gurney 1985; Hamond 1983: 62-4). Absorption was measured after 10 minutes using a spectrophotometer at 470nm transmission (Jackson 1958: 153). Results are expressed as milligrams of phosphorus per 100 grams of soil (Sieveking et al 1973).

\section{Loss on ignition}

Organic content was estimated by measuring LOI after five hours at $550^{\circ} \mathrm{C}$. 


\subsubsection{Results}

\section{Background phosphate concentrations}

Control samples showed that peat deposits at Calanais Fields have a background mean of $250 \mathrm{mgP} / 100 \mathrm{~g}$ and the mean background levels in basal mineral soils are $480 \mathrm{mgP} / 100 \mathrm{~g}$.

\section{Trench 15 grid samples: phosphate concentrations} Phases 1-4

Overall, the results show higher phosphate levels to the west of field boundary wall C15004, where there is a cluster of high concentrations in the central area of $\mathrm{C} 15003$. To the east of wall $\mathrm{C} 15004$ there were fewer concentrations of high phosphate levels, with only a small area of enhancement recorded on the slope of a possible furrow (extension of feature C15012). Similarly, only one high concentration was recorded from within the structure, adjacent to and slightly beneath feature $\mathrm{C} 15018$, a secondary wall blocking the earlier entrance of structure C15008. Higher concentrations from grid positions adjacent to the trench edge correspond with the position of a step into the trench and are likely to represent contamination from trampling.

The high phosphate concentrations in the palaeosol C15003 to the west of wall C15004 are in marked contrast to those encountered in the rest of the site. This suggests the earliest cobbling in the palaeosol to the west of the trench marks a phase of pastoral activity and that the function of this area differed from that elsewhere. These results support the idea that the cobbles were laid down to consolidate the area and to facilitate the movement of animals.

The rate at which phosphates are dispersed across the site and through the soil depends upon the rate of mixing and may be affected by processes such as ploughing and erosion, resulting in uneven distribution. Several higher concentrations occurred to the east of wall C15004, particularly from within the ditch feature and also the ditch behind wall C15004 (C15014 and C15021), highlighting the accumulation of phosphate-rich soil layers here as material was built up behind the wall during Phase 3. These features are stratigraphically related to the agricultural soil and phosphate-rich palaeosol to the west of the wall, supporting the interpretation of intensive human activity. Elsewhere across the site, the remnants of cultivation furrows (to the east of the field wall), may have masked high phosphate concentrations through the redistribution of soil layers. Their presence implies this area may have predominantly been used for arable cultivation, rather than for the grazing of animals. Similarly, the low levels of phosphate from within the structure suggest that this was not a shelter for livestock but had some other purpose, such as storage or a shelter for humans. The results, together with the low number of artefacts recovered from Trench 15 , suggest that the structure was kept clean and quantities of waste material were prevented from accumulating.

The phosphate levels which are interpreted as enhanced above the background mean of $480 \mathrm{mgP} / 100 \mathrm{~g}$, generally fall into the range of 500-1000 mgP/100g. Such levels can be compared with those from Bronze Age agricultural soils at Old Scatness, Shetland, where total phosphorus values range from 711-1515mgP/100g (Simpson et al 1998a: 116). The limited use of domestic refuse and peat ash as amendment materials is suggested by thin-section micromorphology (ibid). Iron Agecultivated soils at the same site contained higher total phosphate values $(1224-1783 \mathrm{mgP} / 100 \mathrm{~g}$ ), with the addition of animal manure to the amendment strategies evident (ibid). Phosphate levels at Calanais Fields are comparable to, though lower than, the Bronze Age soils at Old Scatness. This, with the micromorphological results, suggests that there was no significant addition of domestic refuse or manure to the soils at Calanais Fields.

\section{Phase 5}

Context 15015, the dark brown sandy silt separated from the palaeosol $\mathrm{C} 15003$ by the gritty interface C15002, exhibits low phosphate concentrations. This suggests either a change in function of the cobbling over time or less intensive pastoral agriculture. However, phosphate retention can depend on the sediment in question. Mineralisation and inorganic fixation of organic phosphates occurs as organic matter decomposes in soils. Higher phosphate concentrations would therefore be expected in more minerogenic soils (Crowther 1997). Continued physical weathering will affect the distribution of phosphates within the soil profile 
and small lenses of variable phosphate content may occur (Hamond 1983). Similarly, the lack of mineral material within peat, the presence of only a few, nutrient-poor, plant species on the surface of the peat bog and the highly acidic nature of the peat body means that few phosphates are released and they are highly soluble, giving low phosphate levels throughout the peat (Hamond 1983). In this phase characterised by peaty soil, phosphate concentrations may have been reduced due to the above factors.

\section{Trenches 4, 6-9 and 11 grid samples: phosphate concentrations}

Grid samples of the palaeosol taken from each of these trenches exhibited low phosphate concentrations of between $90 \mathrm{mgP} / 100 \mathrm{~g}$ and $261 \mathrm{mgP} / 100 \mathrm{~g}$, suggesting that human activity had not centred on these areas. These smaller trenches, to the south and downslope of Trench 15, are in an area of deeper peat where the acidic nature of the soil had considerably lowered the natural phosphate concentrations and no evidence for human activity was uncovered. The organic content of these grid samples also shows little variation and predominantly reflects the minerogenic nature of the palaeosol.

\section{Trench 14 section: phosphate concentrations and organic content}

Phosphate levels were analysed at $10 \mathrm{~mm}$ resolution through the west-facing section $(0.88 \mathrm{~m}$ depth) to highlight any anthropogenic activity that was mirrored in the features found further up the hill. Results indicate a peak in phosphate levels at $23-4 \mathrm{~cm}$, which correlates well with the fill of a cut $(\mathrm{C} 14003)$ that was exposed in the section. This feature appeared to be natural in origin and the corresponding lower organic content values suggest it reflects the inwash and accumulation of more minerogenic material. There is another peak in phosphate levels at $61-2 \mathrm{~cm}(540 \mathrm{mgP} / 100 \mathrm{~g})$, corresponding with the levels measured in the palaeosol in Trench 15 . At $56 \mathrm{~cm}$, organic content in Trench 14 drops considerably prior to the rise in phosphate levels. Phosphate content then continues to rise to exceptionally high levels at $75-6 \mathrm{~cm}(1,212 \mathrm{mgP} / 100 \mathrm{~g})$, with organic content remaining low. These basal levels are higher than those seen in Trench 15 but reflect soil samples from beneath the palaeosol. These deposits may represent a mixture of soil from further upslope, some in-situ palaeosol and the accumulation of colluvium (C14009).

This soil, formed on eroded slopes, represents the initial pedogenesis in the area, with very high background phosphate levels. Phosphate levels in the glacial till are slightly reduced. The organic content values through this section also suggest that the main period of peat growth occurred between $15 \mathrm{~cm}$ and $56 \mathrm{~cm}$ and during this time there was little or no anthropogenic disturbance. These conclusions correspond well with the palynological record as this period of undisturbed peat growth commences at the upper boundary of the ancient agricultural occupation phase (PAZ-2) and ceases early in the most recent phase of occupation (PAZ-5b).

\section{Trench 15 section: phosphate concentrations and organic content}

Samples were also taken at $1 \mathrm{~cm}$ intervals through the south-facing section of Trench 15 . Unlike Trench 14, there are several defined peaks in phosphate levels $(28-9 \mathrm{~cm}, 62-3 \mathrm{~cm}, 76-7 \mathrm{~cm}$ and $88-9 \mathrm{~cm})$. They are not high enough to suggest anthropogenic activity, but are interpreted to indicate periods when the blanket peat surface dried out, growth slowed and more minerogenic material accumulated. Phosphate levels, however, do increase towards the base of the profile in the palaeosol (rising to $903.6 \mathrm{mgP} / 100 \mathrm{~g}$ ), recording agricultural activity associated with the palaeosol and the higher phosphate levels in the brown earth. Again, the increased phosphate signals above $30 \mathrm{~cm}$ correspond to the agricultural activity apparent in the palynological record.

The pattern demonstrated with the phosphate levels can similarly be reflected in the organic content curve from the same profile. The slight peaks in phosphate are mirrored with small drops in the organic content of the profile as a result of the bog surface drying out and an accumulation of sands/ silts on the surface. At the peat/palaeosol interface $(106-7 \mathrm{~cm})$, organic content drops considerably and phosphate levels again rise. 


\subsection{Soil micromorphology}

Adrian Tams

\subsubsection{Methodology}

Samples for soil micromorphological analysis were taken from Trenches 15 and 17 (Illus 41) to aid in the interpretation of land use and of the formation processes of the palaeosol and overlying peat. Samples were also taken from inside Structure 15008 (Illus 19), to investigate what the building had been used for.

The thin-sections were produced following the standard methods of acetone drying, resin impregnation and thin-sectioning (Fitzpatrick 1984; Fitzpatrick 1993). The thin-section was first analysed over a light box without magnification, and then under a transmitting light microscope using a range of light sources (plane polarised and crossed polarised) at a range of magnifications. Thin- section descriptions conform to the internationally accepted terminology by Bullock et al (1985), and components and features within the sediments were semi-quantified with the aid of frequency charts in that source.

\subsubsection{Results}

\section{Trench 15: Samples A1-A4 (Illus 19)}

These samples were collected from a section through the northern cell of the structure within Trench 15, with Contexts 15017, 15019, 15020 and 15037 being represented in the thin-sections.

The aim was to determine whether there was any sign of anthropogenic activity within the structure or a possible indication of the use of the structure. The presence of charcoal fragments through most of the thin-sections is the sole micromorphological indication of human activity; the other chief micromorphological signals of human activity,

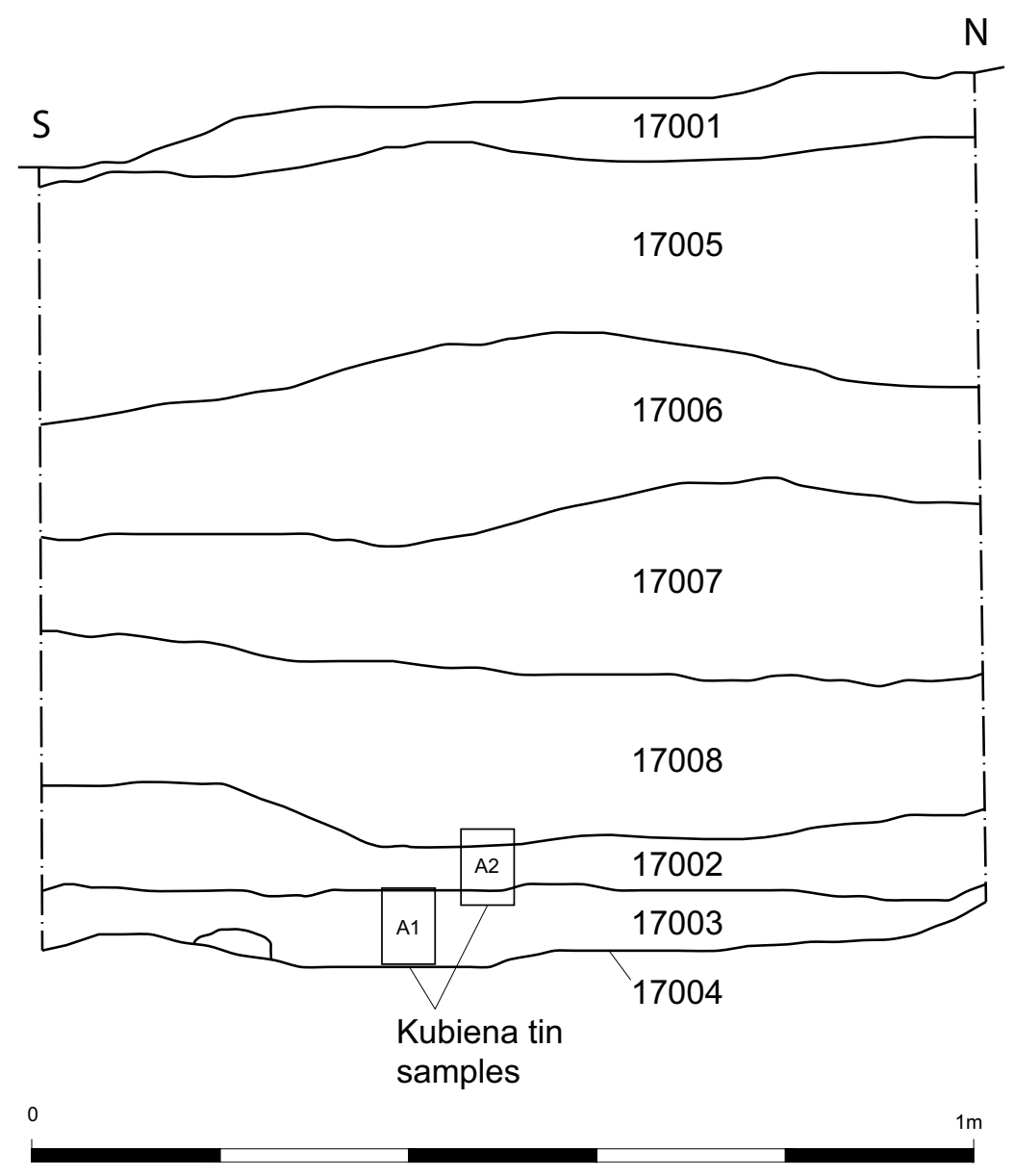

Illus 41 Trench 17 east-facing section 
bone fragments, were not found as they will have decomposed due to the acidic nature of the peat deposits. The charcoal fragments were evident in varying frequencies, from $10 \%$ in $\mathrm{A} 1, \mathrm{~A} 2$ and $\mathrm{A} 3$, decreasing to $2.5 \%$ in $\mathrm{A} 4$.

Section A4 is largely composed of the sub-peat palaeosol. The low frequency of charcoal fragments in the palaeosol is largely a consequence of the low infiltration capacity of the peat, the extended timescale required for this to occur, and also because of the dominant clay matrix and low pore content of the glacial till.

Evidence for trampling within the material was sought. The massive microstructure of the samples (with few or no cracks and voids within the organic matrix) is not suggestive of trampling, which is typically indicated by frequent linear horizontal and vertical cracks and voids. There was no microstratification within the material, which occurs as a result of trampling and is typified by thin lenses occurring throughout the main bulk of the material, indicating local compaction of a surface. The deposits are therefore interpreted as in-situ peat accumulations.

\section{Trench 15: samples B1-B4 (Illus 8)}

These samples were collected from the east side of wall $\mathrm{C} 15004$, through deposits accumulated behind the wall, with Contexts 15002, 1502115034 and 15032 being represented in the thin-sections. The aim was to understand the phasing of agricultural activity and the nature of soil accumulation.

The upper two thin-sections (B1 and B2) are representative of natural peat accumulations, revealing no anthropogenic inclusions or signs of modification by anthropogenic activities.

Sample B3 contained 5\% charcoal fragments, interpreted as anthropogenic inclusions. These fragments were well embedded within the dense organic matrix and will thus have been incorporated into the peat at the time of its accumulation. There is no other indication of the peat having undergone anthropogenic alteration.

Sample B4 largely comprised a brown earth with a high organic content and displaying a dense, dark brown colouration, contrasting in colour with the overlying peat deposits. This soil appears to have been well mixed with peat deposits after its accumulation. The mineral fraction shows strong evidence for anaerobic conditions leading to gleying. The minerals are very coarse-grained, with pebblesized grains dominant, and are unsorted in nature. The sample is also very well mixed with a random arrangement of the grains. It is possible that these grains were purposely added to this highly organic soil to increase its porosity and thereby its drainage potential. Evidence for clay particles in this deposit is perhaps a result of mixing by later ploughing activity (also evidenced by the presence of furrows).

This sample also has a low peat content, possibly added artificially. The peat added is likely to have been well-humified as there is little evidence for any plant remains with visible cellular structure present, aside from coarse root fragments.

In summary, it is clear that sample B4 is representative of an attempt at soil improvement with the addition and mixing of a coarse-grained glacial till to the brown earth. It is possible that a till, low in clay but with a high mineral content, was specifically chosen to enhance the drainage potential of the brown earth and peat soil.

\section{Trench 17: samples A1 and A2 (Illus 41)}

These samples were collected in order to provide a comparison with Trench 15, to investigate whether the possible inclusion of glacial till into the peat was a cross-site phenomenon. However, the micromorphological analysis of these two samples confirms that this was not the case.

All of the micromorphological characteristics present are comparable with the peat samples taken from Trench 15. There is no high incidence of coarse mineral grains, no clay patches/signs of anaerobism, nor any apparent mixing of the sediments.

It is therefore concluded that these samples represent natural peat accumulations with no anthropogenic input into the formation of the deposit.

\subsection{Carbonised plant remains}

\section{Mhairi Hastie}

The plant fractions were scanned to assess the quantity and quality of the palaeoenvironmental remains. It was established that, apart from wood charcoal, which was present in most samples, only a small number of samples contained other carbonised plant remains. The samples identified as 
containing carbonised plant material during initial assessment were fully sorted and all cereal grain and other plant material was removed for identification. Identifications were made with reference to the modern comparative collection of Headland Archaeology Ltd and seed atlases (Berggren 1969; Berggren 1981). Plant nomenclature utilised in the text follows Stace (1997) and Zohary \& Hopf (2000).

\subsubsection{Results}

The recovery of carbonised plant material from the bulk soil samples was low. The majority of samples contained wood charcoal, but this was present only in low concentrations. Carbonised cereal grains and other plant material such as the seeds of wild taxa were recovered, the majority of which came from contexts excavated in Trench 3 (Table 2).

Cereal grains and weed seeds were recovered from a range of contexts in Trench 3 . The cereal grains recovered consisted primarily of oat (Avena sp.), with lesser quantities of hulled barley (Hordeum vulgare). Occasional seeds from wild species were also present, including dock (Rumex sp.), knotgrass (Polygonum spp.), ribwort (Plantago lanceolata), grass family (Poaceae indet.) and one possible caryopsis of heath grass (cf Danthonia decumbens). In addition, small quantities of hazelnut shell were recovered from the majority of samples and carbonised rhizomes were present in C3014.

Low concentrations of carbonised rhizomes and hazelnut shell were recovered from palaeosol deposits excavated in Trenches 8,9 and 15.

\subsubsection{Discussion}

All cereal grains and weed seeds were recovered from deposits associated with a stone-built structure (Trench 3). The cereal grain recovered from these deposits was predominantly oat, with lesser quantities of hulled barley. This predominance of oat throughout the samples and the oat/barley combination is characteristic of cereal grain assemblages from other medieval or later sites for this region. The weed seed assemblages consist of wild taxa commonly associated with grasslands. Their presence together with the cereal grain suggests that these wild taxa were growing with the cereals and thus brought to the site with the harvested crop.

In northern temperate regions it was common practice to dry cereal grain to aid both the removal of awns and the grinding process. In the absence of any obvious conflagration deposits associated with the structure, the likely source of the charred material is from the domestic hearth around which cereal grain could have been dried or prepared for cooking. The presence of burnt material within many unassociated contexts indicates the reworking and redepositing of cereal grain, and the preservation of the carbonised material is probably a reflection of their having been protected from trampling and similar activities.

A deposit of peat ash (C3017) also contained small quantities of oat and barley grain. This ash deposit is believed to be the remains of a hearth. The presence of both oat and barley within this deposit suggests a medieval or later date for the hearth structure and indicates that it may be associated with the structure. The quantity of hazelnut shell was low and could either represent domestic debris discarded onto the fire or material collected with firewood. The presence of carbonised rhizomes, albeit in low concentrations, suggests the possible use of turf for fuel. 


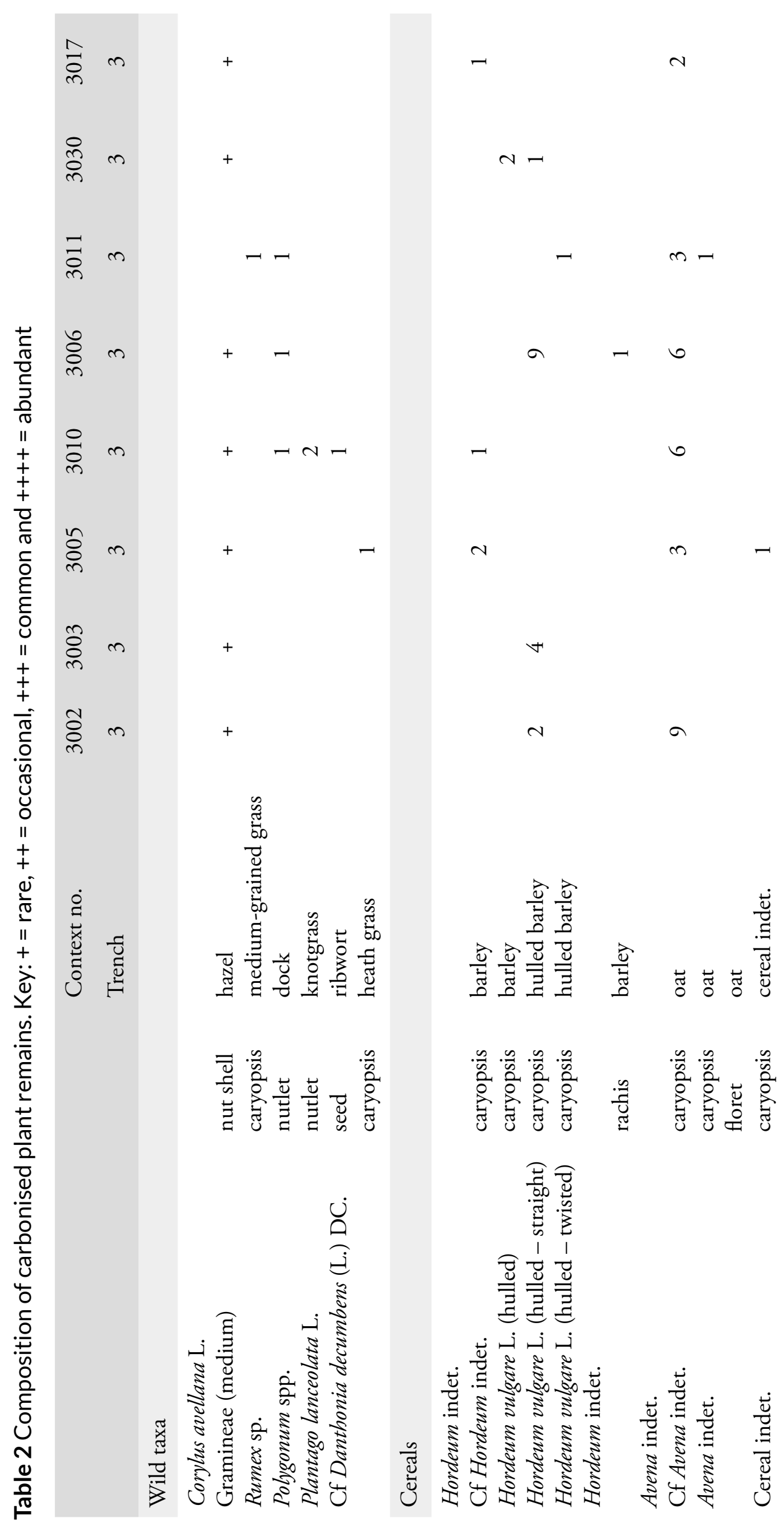

